\title{
Green Thiocyanation of Aromatic and Heteroaromatic Compounds by Using Silica Boron Sulfonic Acid as a New Catalyst and $\mathrm{H}_{2} \mathrm{O}_{2}$ as Mild Oxidant
}

\author{
Sami Sajjadifar \\ Department of Chemistry, Faculty of Science, Ilam University, P.O. Box 69315516, Ilam, Iran and Department of Chemistry, Payame Noor \\ University, PO BOX 19395-4697 Tehran, Iran
}

\begin{abstract}
Highly efficient regioselective thiocyanations of indoles and $N, N$-disubstituted anilines are achieved via a green and simple protocol using Silica Boron Sulfonic Acid (SBSA) as a new catalyst, KSCN and hydrogen peroxide as a mild and environmentally friendly oxidant in aqueous condition.
\end{abstract}

Keywords Silica Boron Sulfonic Acid, SBSA, BSA, Thiocyanation, Green Synthesis, Hydrogen Peroxide

\section{Introduction}

Thiocyanates play an important role in organic synthesis[1] and in pharmaceuticals[2]. Thiocyanate is a versatile synthon which can be readily transferred to other functional groups such as sulfide[3], aryl nitrile[4], thiocarbamate[5], and thionitrile[6]. Therefore, it is important to find the new and fast methods for synthesis of thiocyanate group containing aromatic systems[7]. In view of the versatility of thiocyanate group in heterocyclic construction[8], it will be of significance to probe the thiocyanation of aromatic and heteroaromatic compounds. Several methods have been developed for the thiocyanation of arenes by using various reagents under certain conditions[9-18]. Yet, only a limited number of reagents, such as bromine/potassium thiocyanate (only for indoles)[15], N-thiocyanatosuccinimide (only for 5- methoxy-2-methylindole and accompanied by two bisthiocyanates)[16], ceric ammonium nitrate (CAN)[17], acidic mont K10 clay[18], iodine/methanol, oxone[19], diethyl azodicarboxylate[20], IL-OPPh2[21], potassium peroxydisulfate-copper(II)[22], have been applied to the thiocyanation of aromatic and heteroaromatic systems. However, these methodologies suffer from one or more drawbacks such as the less availability or hard preparation of starting materials[15-16], the requirement for a large excess of strong oxidizing reagents, low yields for some compounds[17], and performances under certain special conditions[18]. Hence, a requirement for developing alternative synthesis routines accessible to the thiocyanation of aromatic and heteroaromatic compounds is in high demand. Avoiding organic volatile solvents during the reactions in organic synthesis leads to a clean, efficient, and

* Corresponding author:

ss_sajjadifar@yahoo.com (Sami Sajjadifar)

Published online at http://journal.sapub.org/ajoc

Copyright (C 2012 Scientific \& Academic Publishing. All Rights Reserved economical technology.

There is an increasing interest in the use of environmentally benign reagents and procedures. In other words, the presence of green solvent coupled with the high yields and short reaction times often associated with reactions of this type make these procedures very attractive for synthesis[23]. Aqueous mediated reactions have received considerable attention in organic synthesis due to the environmental safety reasons. Water is a desirable solvent for chemical reactions because it is safe, non-toxic, environmentally friendly, readily available, and inexpensive compared to organic solvents[24-26]. It has high dielectric constant and cohesive energy density compared to organic solvents. It has also special effects on reactions arising from inter and intramolecular non-covalent interactions leading to novel solvation and assembly processes. Water as a reaction medium has been utilized for large numbers of organic reactions[27]. Thus, the development of an efficient and convenient synthetic methodology in aqueous medium is an important area of research[28-29]. However, most of the catalysts are expensive and may lead to the environmental pollution. With the overgrowth of environmental and economic concerns, the development of benign catalytic processes for organic reaction is becoming increasingly important[30]. The solvent effect on product yields was investigated using 1a as a substrate. Both the yields and reaction times listed in Table 1 suggest that water appears to be very favorable for thiocyanations in presence of SBSA (as a strong and new catalyst).

Table 1. Solvent effects on the thiocyanation of 1a

\begin{tabular}{ccc|}
\hline Solvent & Time(h;min) & Yield\%" $^{\mathbf{a}}$ \\
\hline Water & $\mathbf{0 0 : 0 5}$ & $\mathbf{9 8}$ \\
Acetonitrile & $01: 20$ & 80 \\
Tetrahydrofurane & $02: 00$ & 73 \\
Dichloromethane & $08: 00$ & 70 \\
Carbon tetrachloride & $12: 00$ & 47 \\
Ethanol & $00: 30$ & 89 \\
\hline
\end{tabular}

${ }^{\mathrm{a}}$ The reaction time.

${ }^{\mathrm{b}}$ Isolated yield of the products after column chromatograph 
Table 2. Substrate scope in the thiocyanation reaction of arenes using $\mathrm{KSCN} / \mathrm{SBSA} / \mathrm{H}_{2} \mathrm{O}_{2}$

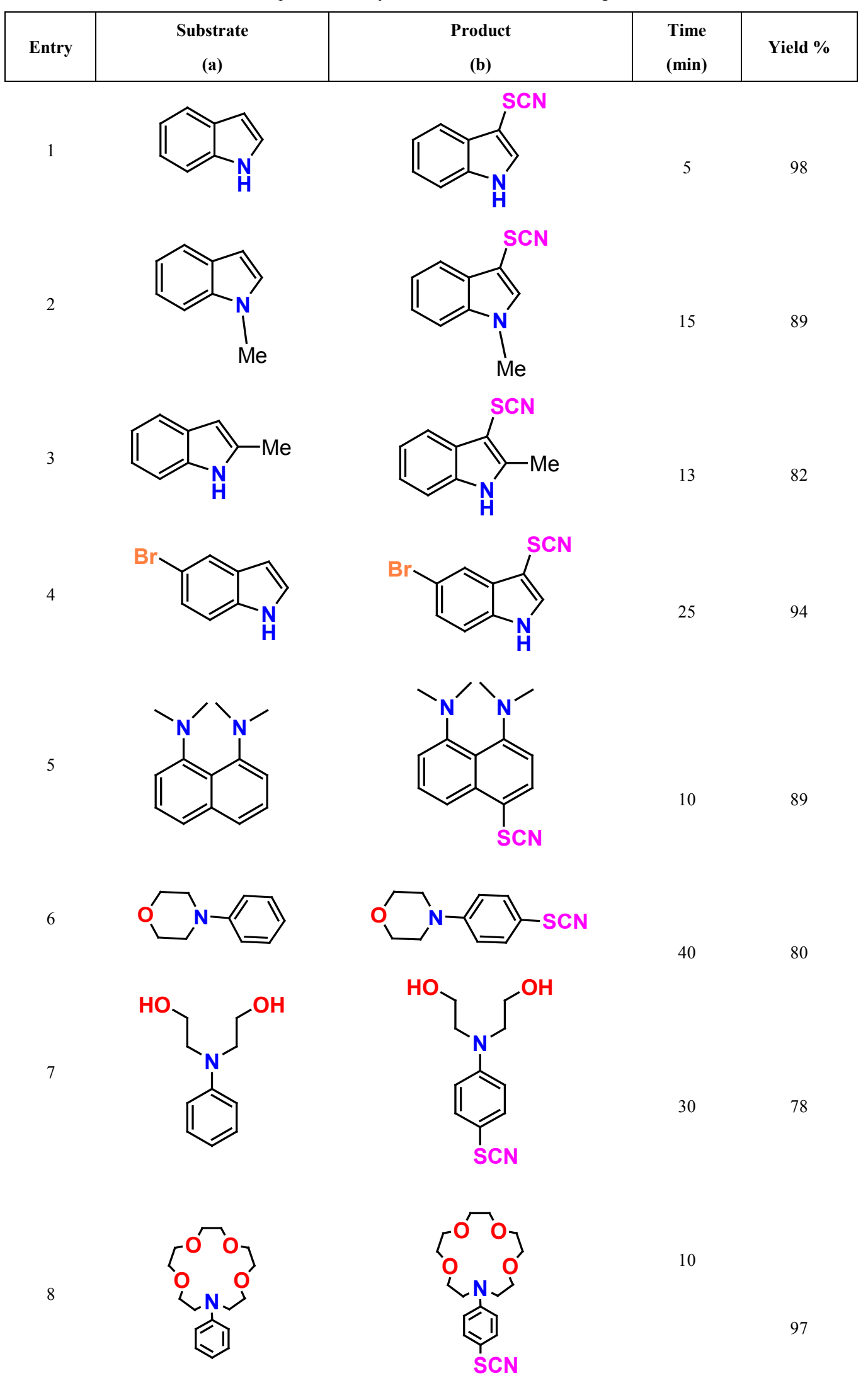


9<smiles>CN(C)c1ccccc1</smiles>

10<smiles>CCN(CC)c1ccccc1</smiles>

11<smiles>c1ccc2c(c1)CCN2</smiles><smiles>CN(C)c1ccc([As]=N)cc1</smiles><smiles>CCN(CC)c1ccc([Se]#N)cc1</smiles><smiles>N#Sc1ccc2c(c1)CCN2</smiles><smiles>N#Sc1ccc2c(c1)CCCN2</smiles>

14

10 92<smiles>c1ccc2c(c1)CCCN2</smiles><smiles>N#Sc1ccc(N2CCNCC2)cc1</smiles>
60 $45^{\mathrm{a}}$

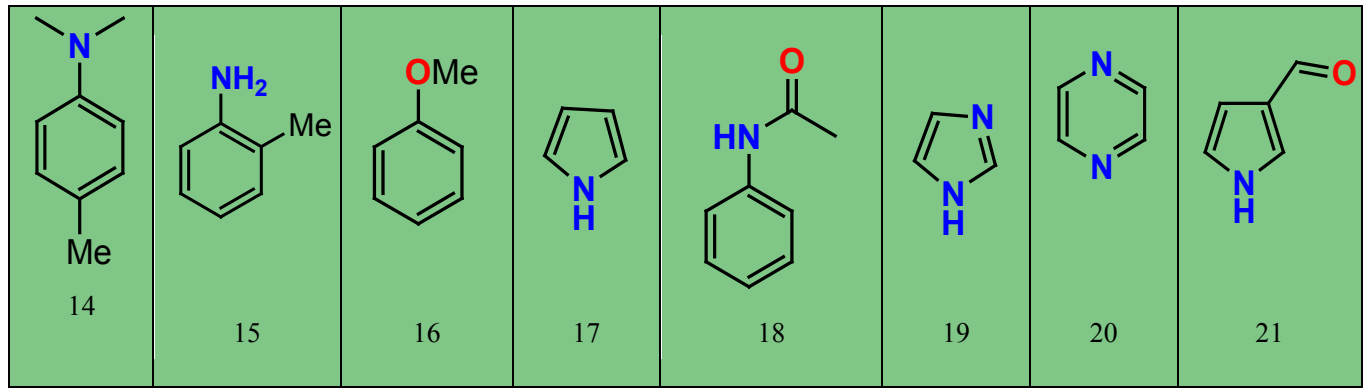

${ }^{\mathrm{a}}$ These reactions were not complete (by using tlc )

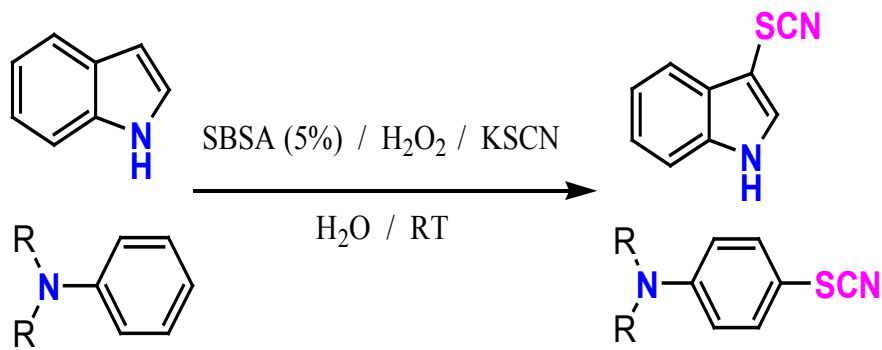

Scheme 1. Thiocyanation reaction by using SBSA as a new catalyst<smiles>OB(O)O</smiles>

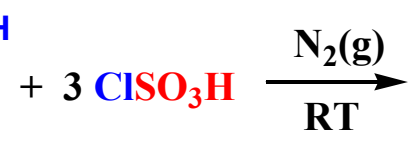<smiles>O=S(=O)(O)OB(O[Sb](=O)(=O)O)S(=O)(=O)O</smiles>

\section{$+3 \mathrm{HCl}(\mathrm{g})$}

SBSA

Scheme 2. Production of SBSA

Typically $\mathrm{HCl}$ was used to catalyze the wide range of organic reactions or used as a Bronsted co-catalyst in combination with Lewis acid such as $\mathrm{AlCl}_{3}$ in the transalkylation and isomerization reactions [31-34]. Aqueous hydrogen peroxide was also utilized as terminal oxidant[35], due to the effective oxygen content, low cost and environmentally friendly character.

Firstly, SBSA was introduced by A. R. Kiasat (Scheme 2) and used for the regioselective conversion of epoxides to thiocyanohydrins under solvent-free reaction conditions[36]. 


\section{Methods}

\subsection{General}

Chemicals were purchased from Merck chemical company. Yields refer to isolated products. Thiocynation of indole to 3-thiocyanato indole. A typical procedure: A suspension of indole $(0.117 \mathrm{~g}, 1 \mathrm{mmol})$, potassium thiocyanate $(0.294 \mathrm{~g}, 3 \mathrm{mmol})$, SBSA $(0.05 \mathrm{~g}, 5 \%)$ in $\mathrm{H}_{2} \mathrm{O}$ $(7-10 \mathrm{~mL})$ was stirred at room temperature for 5-10 min. then $\mathrm{H}_{2} \mathrm{O}_{2}(0.45 \mathrm{~mL})$ was added dropwise $(2-5 \mathrm{~min})$. The progress of the reaction was monitored by TLC (ethylacetate: n-hexane 1:10). After completion of the reaction, the reaction mixture was decanted with $\mathrm{CHCl}_{3}(3 \times 20 \mathrm{~mL})$. Anhydrous $\mathrm{Na}_{2} \mathrm{SO}_{4}(5 \mathrm{~g})$ was added to the organic layer and filtered off after $20 \mathrm{~min}$. Chloform was removed. The yield was $0.167 \mathrm{~g},(96 \%)$, dark brown solid mp $71-73{ }^{\circ} \mathrm{C}$ (1b) $[2,19,37]$. FT-IR (KBr): 2159, 3289, ${ }^{1} \mathrm{H}-\mathrm{NMR}$ (FT-300 $\left.\mathrm{MHz}, \mathrm{CDCl}_{3} / \mathrm{TMS}\right)$ : dppm 8.87 (1H, br s, NH), $7.83(1 \mathrm{H}, \mathrm{d}$, $\mathrm{J}=8.8 \mathrm{~Hz}), 7.46-7.23(4 \mathrm{H}, \mathrm{m}) .{ }^{13} \mathrm{C}$ NMR $(75 \mathrm{MHz}, \mathrm{CDCl} 3)$ : $136.06,131.22,127.66,123.83,121.87,118.65,112.24$, 91.76.

\subsection{Preparation of Silica Boron Sulfonic Acid (SBSA)[36]}

A $50 \mathrm{~mL}$ suction flask was equipped with a constant pressure dropping funnel. The gas outlet was connected to a vacuum system through an adsorbing solution (water) and an alkali trap. Boric acid $(1.55 \mathrm{~g}, 25 \mathrm{mmol})$ was charged in the flask and chlorosulfonic acid $(8.74 \mathrm{~g}$, ca. $5 \mathrm{~mL}, 75 \mathrm{mmol}$ in 5

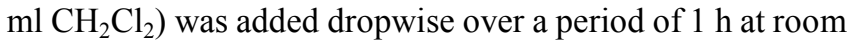
temperature under $\mathrm{N}_{2}$ gas. $\mathrm{HCl}$ evolved immediately. After completion of the addition, the mixture was shaken for 85 min, while the residual $\mathrm{HCl}$ was eliminated by suction. Then the mixture was washed with diethyl ether to remove the unreacted chlorosulfonic acid and then add $14.4 \mathrm{~g} \mathrm{SiO}_{2}$ and mix. Finally, dried and a grayish solid material was obtained in $95.66 \%$ yield $(21.6 \mathrm{~g}) .{ }^{1} \mathrm{HNMR}$ of BSA in Acetone-D6 show $\delta=12.218$.

\subsection{Selected Specteral Data}

\subsubsection{1-Methyl-3-thiocyanato Indole(2b)[2,19,37]}

White brown solid m.p 76-78 ${ }^{\circ} \mathrm{C}$ FT-IR (kbr): $2146 \mathrm{~cm}-1$, 1H-NMR (FT-300 mhz, cdcl3/TMS): dppm 7.84-7.36 (5H, m), $3.74(3 \mathrm{H}, \mathrm{s}) .{ }^{13} \mathrm{CNMR}\left(75 \mathrm{MHz}, \mathrm{CDCl}_{3}\right): 137.17,135.22$, $128.47,123.45,121.62,118.88,112.106,110.36,33.42$.

\subsubsection{2-Methyl-3-thiocyanato Indole(3b)[2,19,37]}

Brown solid, mp 104-106 ${ }^{\circ} \mathrm{C}$, FT-IR (kbr): $2151 \mathrm{~cm}^{-1}$, $3395 \mathrm{~cm}-1,{ }^{1} \mathrm{H}-\mathrm{NMR}$ (FT-300 MHz, CDCl3/TMS): dppm $8.65(1 \mathrm{H}, \mathrm{br} \mathrm{s}, \mathrm{NH}), 7.71(1 \mathrm{H}, \mathrm{d}, \mathrm{J}=8.8 \mathrm{~Hz}), 7.33-7.23(3 \mathrm{H}$, $\mathrm{m}), 2.5(3 \mathrm{H}, \mathrm{s}) .{ }^{13} \mathrm{C} \mathrm{NMR}\left(75 \mathrm{MHz}, \mathrm{CDCl}_{3}\right): 142.152,135.14$, $128.69,122.96,121.55,118.04,111.30,88.72,12.05$.

\subsubsection{5-Bromo-3-thiocyanato Indole $(4 b)[2,19,37]$}

White brown solid mp 114-116 ${ }^{\circ} \mathrm{C}$, FT-IR (KBr): 2146, $3351 \mathrm{~cm}^{-1},{ }^{1} \mathrm{H}-\mathrm{NMR}$ (FT-300 MHz, $\mathrm{CDCl}_{3} / \mathrm{TMS}$ ): dppm 8.87
(1H, br s, NH), 7.90- $7.15(5 \mathrm{H}, \mathrm{m}),{ }^{13} \mathrm{C}$ NMR $(75 \mathrm{MHz}$, $\left.\mathrm{CDCl}_{3}\right): 134.68,132.29,129.32,123.15,121.27,115.37$, 113.72, 111.98, 102.212.

\subsubsection{N1,N1,N8,N8-Tetramethyl-4-thiocyanato Naphthalene-1,8-Diamine(5b)}

Gray solid, m.p 79-8 ${ }^{\circ} \mathrm{C}, \mathrm{FT}-\mathrm{IR}$ (kbr): $2055 \mathrm{~cm}^{-1},{ }^{1} \mathrm{H}-\mathrm{NMR}$ (FT-300 MHz, $\left.\mathrm{CDCl}_{3} / \mathrm{TMS}\right)$ : dppm 7.97-7.66 (5H, m,), 3.37 $(12 \mathrm{H}, \mathrm{s}) .{ }^{13} \mathrm{C}$ NMR $\left(75 \mathrm{MHz}, \mathrm{CDCl}_{3}\right): 148.23,144.64$, 135.14, 132.6, 129.36, 127.12, 121.38, 120.7, 118.04, 115.4, $111.30,46.97$.

\subsubsection{4-Thiocyanato N-phenyl Morpholine(6b)}

Brown solid mp 75-77 ${ }^{\circ} \mathrm{C}$, FT-IR (KBr): $2156 \mathrm{~cm}^{-1}$. ${ }^{1} \mathrm{H}-\mathrm{NMR}$ (FT-300 MHz, $\left.\mathrm{CDCl}_{3} / \mathrm{TMS}\right)$ : dppm 7.48-7.40 $(2 \mathrm{H}$, $\mathrm{d}, \mathrm{J}=8.4), 6.92-6.85(2 \mathrm{H}, \mathrm{d}, \mathrm{J}=8.4), 3.88-3.85(\mathrm{t}, 4 \mathrm{H}, \mathrm{t}, \mathrm{J}=4.5)$, 3.24-3.21 (4H, t, J=4.5). ${ }^{13} \mathrm{C}$ NMR (75 MHz, $\left.\mathrm{CDCl}_{3}\right): 152.54$, $133.78,116.19,111.97,111.17,67.15,48.06$.

\subsubsection{4-Thiocyanato N-phenyl-2,2-iminodiethanol(7b)}

Dark brown solid mp $67-69^{\circ} \mathrm{C}$, FT-IR (kbr): 2153, 3300 $\mathrm{cm}^{-1}{ }^{1} \mathrm{H}-\mathrm{NMR}$ (FT-300 mhz, $\mathrm{cdcl}_{3} /$ TMS): dppm 7.43-7.33 $(2 \mathrm{H}, \mathrm{d}, \mathrm{J}=7.2), 6.70-6.61(2 \mathrm{H}, \mathrm{d}, \mathrm{J}=7.2), 3.75-3.60(4 \mathrm{H}, \mathrm{m})$, 3.55-3.35 (4H, m), $2.15(2 \mathrm{H}, \mathrm{s}) .{ }^{13} \mathrm{C}$ NMR $\left(75 \mathrm{MHz}, \mathrm{CDCl}_{3}\right)$ : $151.8,132.1,116.5,114.3,111.7,58.72,55.9$.

\subsubsection{4-Thiocyanato N-phenyl 15-crown-5(8b)}

Brown solid, m.p 78-80 ${ }^{\circ} \mathrm{C}$ FT-IR (kbr): 2147, $1094 \mathrm{~cm}^{-1}$. ${ }^{1} \mathrm{H}-\mathrm{NMR}$ (FT-300 MHz, $\mathrm{CDCl}_{3}$ /TMS): dppm 7.35-7.37 (2H, $\mathrm{d} \mathrm{J}=8.2)$, 6.64-6.62 (d, 2H, J=8.2), 3.57-3.72 $(20 \mathrm{H}, \mathrm{m}) .{ }^{13} \mathrm{C}$ NMR (75 MHz, $\left.\mathrm{CDCl}_{3}\right)$ : 149.32, 134.77, 112.80, 105.94, $112.65,71.26,70.22,69.98,68.01,52.67$.

\subsubsection{4-Thiocyanato N,N-dimethyl Aniline(9b)[2,19,37]}

Dark brown solid, mp $72-73^{\circ} \mathrm{C}$, FT-IR (kbr): $2146 \mathrm{~cm}^{-1}$, 1H-NMR (FT-300 mhz, cdcl $_{3} /$ TMS): dppm 7.44-7.41(2H, d, $\mathrm{J}=8.8), 6.69-6.67(2 \mathrm{H}, \mathrm{d}, \mathrm{J}=8.8), 3.007$ (6H, s). ${ }^{13} \mathrm{C}$ NMR (75 $\left.\mathrm{MHz}, \mathrm{CDCl}_{3}\right): 151.67,134.52,113.13,112.702,106.37$, 40.16 .

\subsubsection{4-Thiocyanato $\mathrm{N}, \mathrm{N}-$ diethyl Aniline(10b)[2,19,37]}

Brown-red Liquid, FT-IR (KBr): $2151 \mathrm{~cm}^{-1}{ }^{1} \mathrm{H}-\mathrm{NMR}$ (FT-300 MHz, $\left.\mathrm{CDCl}_{3} / \mathrm{TMS}\right)$ : dppm 7.5-7.15 (4H), $3.43(4 \mathrm{H}$, q) $1.14(6 \mathrm{H}, \mathrm{t}) .{ }^{13} \mathrm{C}$ NMR $\left(75 \mathrm{MHz}, \mathrm{CDCl}_{3}\right): 149.65,134.97$, $125.28,121.78,112.68,44.56,12.30$.

\section{Results and Discussion}

In order to find a suitable catalyst for thiocyanation reaction in presence of $\mathrm{H}_{2} \mathrm{O}_{2}$ as a mild oxidant[38-39] from indole was chosen as a model to provide compound $1 \mathrm{~b}$ (Scheme 4), and its behavior was studied in various solvents at room temperature. For chosen better solvent, different solvents were examined (Table 1). Water is a desirable solvent for chemical reactions for reasons of cost, safety and environmental concerns, use of water in this reaction gave 
good yields of products. The optimum yields of the products are obtained when $5 \mathrm{~mol} \%$ of SBSA is used. Total reactions are summarized in Table 2. The thiocyanation was investigated in various conditions. In the absence of SBSA, reaction was not accomplished, but in the presence of SBSA $5 \%\left(0.05 \mathrm{~g} \mathrm{SBSA}\right.$ equal $\left.0.15 \mathrm{mmol} \mathrm{H}^{+}\right)$the reaction took place with best result. The stoichiometry of the reactants was also varied. A ratio of 1:3:4 (indole: $\mathrm{KSCN}: \mathrm{H}_{2} \mathrm{O}_{2}$ ) was found to be the most suitable, and decreasing the amount of $\mathrm{H}_{2} \mathrm{O}_{2}$ or potassium thiocyanate increased the reaction time and lowered the yield. The substrate scope of this reaction was then examined using various arenes under the optimized conditions (Table 2). In general, this reaction provided good-to-excellent yields with all the substrates tested. As shown in Table 2, indole and electron-rich indoles gave the desired products in excellent yields (Table 2, entries 1-3). Also, electron- deficient indoles such as 5- bromoindole reacted with potassium thiocyanate and $\mathrm{SBSA} / \mathrm{H}_{2} \mathrm{O}_{2}$ to afford the corresponding 5-bromo-3- thiocyanato indole in good yield, but required longer reaction time (Table 2, entry 4). This observation can be attributed to the lower electron density of such substrates. The lower yield is probably attributed to the steric hindrance of 2- substituted indole (Table 2, entries 3 ). The addition was highly regioselective occurring at the 3-position of the indole ring. ${ }^{19,37}$ Various $\mathrm{N}, \mathrm{N}$-disubstituted aromatic amines were converted into the respective 4-thiocyanato amine in high to excellent overall yields (Table 2, entries 5-10). The reactions were clean and the products were obtained with high para-selectivity (Table 2 , entry 9,10$)$. However, in the case of a parasubstituted amine, ortho thiocyanation did not occur (Table 2, 14). When indoline was used as a substrate, the reacion was not complete (Table 2, entry 11). The same result was shown for 1,2,3,4 tetrahydroquinoline(Table 2, entry 12) and 1phenylpiperazine (Table 2, entry 13). On the other hand, $N, N, 4$-trimethylaniline, o-methylaniline,anisole, pyrole, acetanilide, imidazole, pyrazine and 3-carbaldehydepyrole (Table 2, 14-21) did not react with potassium thiocyanate and $\mathrm{SBSA} / \mathrm{H}_{2} \mathrm{O}_{2}$ to afford the corresponding derivatives. In comparison with other reported methods using other reagents which require refluxing conditions, the assistance of ultrasonic irradiation, toxic solvent or oxidant, this method works under milder and green reaction conditions.

A proposed reaction mechanism is shown in scheme 3. In the first step, $\mathrm{H}_{2} \mathrm{O}_{2}$ reacts with SBSA $\left(\mathrm{H}^{+}\right)$to produce in situ hydrogen peroxonium ion $\left(\mathrm{H}_{3} \mathrm{O}_{2}^{+}\right)$. We have shown that the counter ion of acid did not have any role in the course of the reaction so that $\mathrm{H}_{2} \mathrm{SO}_{4}$ acts the same as $\mathrm{HCl}$. Subsequently, reaction of this cation with $\mathrm{SCN}$ generates $\mathrm{HOSCN}$, which in the presence of $\mathrm{H}^{+}$is able to produce thiocyanium ion $(\mathrm{S}-\mathrm{CN})^{+}$and $\mathrm{H}_{2} \mathrm{O}$. In the last step electrophilic substitution of thiocyanium ion $(\mathrm{SCN})^{+}$with indole will generate the corresponding indolethiocyanate.

\section{Conclusions}

We have found that SBSA is also active as a new catalyst towards the thiocyanation of aromatic compounds using $\mathrm{H}_{2} \mathrm{O}_{2}$ as oxidant (Scheme 1). The protocol reported here is mild and efficient for the thiocyanation of aromatic and heteroaromatic compounds. The mild reaction conditions, environmentally friendly oxidant and solvent, short reaction time and low cost are the obvious advantages of the present method. To identify new conditions for the synthesis of aryl thiocyanates, we began with an investigation of the conversion of indole into the corresponding indole thiocyanate using $\mathrm{SBSA} / \mathrm{H}_{2} \mathrm{O}_{2} / \mathrm{KSCN}$ in the water as a model reaction (Scheme 4).

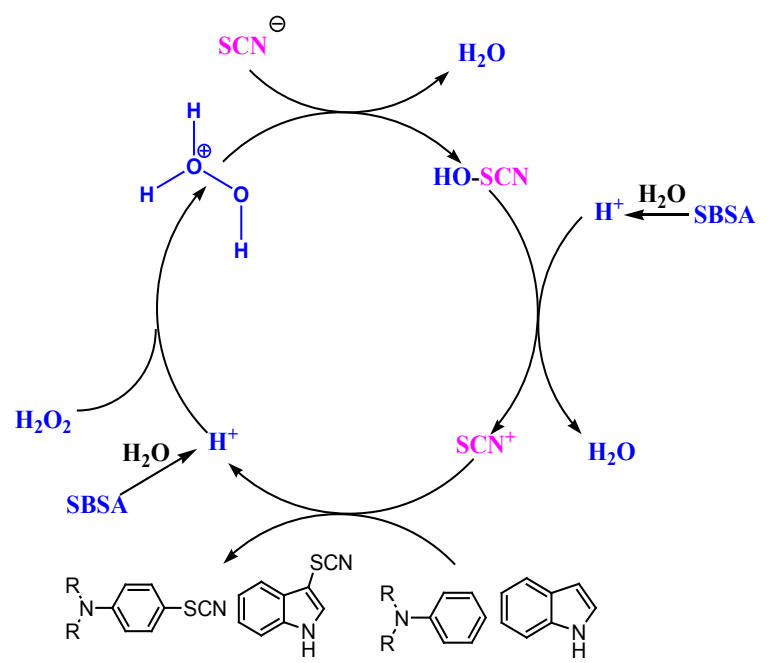

Scheme 3. Proposed mechanism for the thiocyanation of indole and N,N-dialkylaniline<smiles></smiles>

Scheme 4. Indole thiocyanation

To conclude, we have developed an efficient, simple and green mediated thiocyanation of aromatic compounds with high regioselectivity. This procedure offers advantages such as simple work-up short reaction time, low cost of reagents, mild reaction conditions and clean formation of the desired products in high yields.

\section{ACKNOWLEDGEMENTS}

The authors gratefully acknowledge partial support of this work by Payame Noor University (PNU) of Ilam.

\section{REFERENCES}

[1] R. G. Guy, In the Chemistry of Cyanates and their Thio Derivatives; S. Patai, Ed.; John Wiley and Sons: New York, 1977. 
[2] J. S. Yadav, B. V. S. Reddy, S. Shubashree and K. Sadashiv, Tetrahedron Lett., 2004, 45, 2951.

[3] (a) T. Billard, B. R. Langlois and M. Medebielle, Tetrahedron Lett., 2001, 42, 3463; (b) T. Nguyen, M. Rubinstein and C. Wakselman, J. Org. Chem., 1981, 46, 1938; (c) T. Billard, S. Large and B. R. Langlois, Tetrahedron Lett., 1997, 38, 65; (d) P. A. Grieco, Y. Yokoyama and E. Williams, J. Org. Chem. 1978, 43, 1283.

[4] Z. H. Zhang and L. S. Liebeskind, Org. Lett., 2006, 8, 4331.

[5] (a) R. Riemschneider, F. Wojahn and G. Orlick, J. Am. Chem. Soc., 1951, 73, 5905; (b) R. Riemschneider, J. Am. Chem. Soc., 1956, 78, 844.

[6] Y. T. Lee, S. Y. Choi and Y. K. Chung, Tetrahedron Lett., 2007, 48, 5673 and references cited therein.

[7] H. R. Memarian, I. Mohammadpoor-Baltork and K. Nikoofar, Ultrasonics Sonochem., 2008, 15, 456-462.

[8] J. L. Wood, In Organic Reactions; R. Adams, Ed.; John Wiley and Sons: New York, 1946, 3, Chapter 6.

[9] E. Soderback, Acta Chem. Scand., 1954, 8, 1851.

[10] A. B. Angus and R. G. R. Bacon, J. Chem. Soc., 1958, 774.

[11] S. Uemura, M. Okano and K. Ichikawa, Bull. Chem. Soc. Jpn., $1973,46,3254$

[12] S. Uemura, A. Onoe, H. Okazaki and M. Okano, Bull. Chem. Soc. Jpn., 1975, 48, 619.

[13] Y. Kita, T. Takada, S. Mihara, B. A. Whelan and H. Tohma, J. Org. Chem., 1995, 60, 7144.

[14] A. Khazei, A. Alizadeh and R. G. Vaghei, Molecules, 2001, 6, 253.

[15] M. S. Grant, and H. R. Snyder, J. Am. Chem. Soc., 1960, 82, 2742.

[16] F. D. Toste, V. D. Stefano and I. W. J. Still, Synth. Commun., 1995, 25, 1277.

[17] V. Nair, T. G. George, L. G. Nair and S. B. Panicker, Tetrahedron Lett., 1999, 40, 1195.

[18] M. Chakrabarty and S. Sarkar, Tetrahedron Lett., 2003, 44, 8131- 8133 .

[19] G. Wu, Q. Liu, Y. Shen, W. Wu, and L. Wu, Tetrahedron Lett., 2005, 46, 5831.

[20] N. Iranpoor, H. Firouzabadi, D. Khalili and R. Shahin, Tetrahedron Lett., 2010, 51, 3508- 3510.
[21] N. Iranpoor, H. Firouzabadi and R. Azadi, Tetrahedron Lett., 2006, 47, 5531.

[22] A. Kumar, P. Ahamd and R. A. Maurya, Tetrahedron Lett., 2007, 48, 1399-1401.

[23] M. Kidwai, Pure Appl. Chem., 2006, 78, 1983.

[24] C. J. Li and T. H. Chan, Organic reactions in aqueous media.,Wiley, New York 1997.

[25] P. A. Grieco, Organic synthesis in water. Thomson Science, Glasgow, Scotland, 1998.

[26] C. J. Li, Chem. Rev., 2005, 105, 3095.

[27] (a) S. Naik, G. Bhattacharjya, B. Talukdar and B. K. Patel, Eur. J. Org. Chem., 2004, 1245. (b) S. Naik, G. Bhattacharjya, V. R. Kavala and B. K. Patel, Arkivoc, 2004, 1, 55.

[28] B. P. Bandgar, P. E. More, V. T. Kamble and J. V. Totre, Arkivoc, 2008, xv, 1-8.

[29] M. M. Heravi, B. Baghernejad and H. A. Oskooie, Mol. Divers., 2009, 13, 385-387.

[30] Z. W. Wang, Q. X. Kang, F. Quan and Z. Q. Lei, J. Mol. Catal. A Chem., 2006, 261, 190.

[31] D. A. McCaulay and A. P. Lien, J. Am. Chem. Soc., 1952, 74, 6246.

[32] R. H. Allen, L. D. Yats and D. S. Erley, J. Am. Chem. Soc., $1960,82,4853$.

[33] S. U. Choi, W. C. Frith and H. C. Brown, J. Am. Chem. Soc., $1966,88,4128$.

[34] G. A. Olah, M. W. Meyer and N. A. Overchuk, J. Org. Chem., 1964, 29, 2313.

[35] S. Uemura, Oxidation of sulfur, selenium and tellurium, in: B.M. Trost (Ed.), Comprehensive Organic Synthesis, Pergamon Press, Oxford, 1991, 7, 757-787.

[36] Kiasat, A. R.; Fallah-Mehrjardi, J. Braz. Chem. Soc. 2008, 19, $1595-1599$

[37] X. Q. Pan, M. Y. Lei, J. P. Zou and W. Zhang, Tetrahedron Lett., 2009, 50, 347-349.

[38] Ardeshir Khazaeia, Mohammad Ali Zolfigol, Mohammad Mokhlesi, Fateme Derakhshan Panah, sami sajjadifar, , Helvetica Chimica Acta, 2012, Vol. 95. 106-114.

[39] Mohammad Ali Zolfigol1, Ardeshir Khazaei, Hooshang Vahedi, Mohammad Mokhlesi, Sami Sajadifar and Mahtab Pirveysian, ,Phosphorus, Sulfur, and Silicon and the Related Elements, 2012, 187(3), 295-304. 